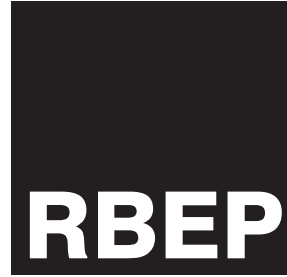 \\ ESTUDos RBEP}

\section{Delimitação de atribuições educacionais: sistemas de ensino e competência constitucional $^{*}$}

Magno Federeci Gomes

\section{Resumo}

A Constituição da República Federativa do Brasil de 1988 desejou o estabelecimento de um pacto federativo cooperativo e integrador, para conceder autonomia às entidades federadas, acercando a administração pública dos cidadãos em suas regiões e localidades. No âmbito educacional brasileiro, a repartição de competências materiais demonstra atribuições concorrentes e descentralizadoras, objetivando uma cooperação recíproca entre os entes federados, cada qual em sua área específica de execução. Este artigo é teórico-documental, mais precisamente jurídico-propositivo. Pode-se concluir que a realidade demonstra, sem sombra de dúvida, as melhores condições dos órgãos do sistema federal de ensino em avaliar as instituições de ensino superior, privadas e públicas, federais, estaduais ou municipais, o que enseja alteração legislativa.

Palavras-chave: direito educacional; competência em matéria educacional; sistemas de ensino; atribuições específicas dos entes federados.
* O presente artigo é resultado da investigação pós-doutoral em Direito Público, na Universidade Nova de Lisboa - Portugal, fomentada pela Coordenação de Aperfeiçoamento de Pessoal de Nível Superior (Capes) do Ministério da Educação brasileiro. 


\section{Abstract \\ Delimitation of educational attributions: learning systems and constitutional competencies}

The Brazilian Federal Constitution (1988) introduced an integrative and cooperative federative pact to give more autonomy to the federated entities and to approximate citizens and the local public administration. In Brazilian education, the division of material competencies shows that there are decentralized and parallel attributions that aim at the cooperation of the entities of federation, each one in a specific area of execution. This article is a theoretical-documentary work, more precisely a juridical-propositive work. One can conclude that reality provides the best conditions for the federal education system to assess higher education institutions, private and public, federal, state or municipal, what urges legal changes.

Keywords: education legislation, educational competencies, education systems, specific attributions of federal entities.

\section{Introdução}

A palavra jurisdição deriva do latim jurisdictio. É formada das expressões jus dicere ou juris dictio, sendo modo de administrar a justiça mediante um paradigma democrático inserido pela Constituição da República Federativa do Brasil de 1988 (CR/88). Em sentido amplo, "jurisdição quer significar todo poder ou autoridade conferida à pessoa, em virtude da qual pode conhecer de certos negócios públicos e os resolver" (Silva, De P. 1998a, p. 466); assim, trata-se de um poder que define a "medida das atividades funcionais da pessoa, seja juiz ou autoridade de outra espécie". Com isso, jurisdição é o poder dever do Estado em dizer o direito, solucionando os conflitos de interesses e resolvendo questões de interesse público, prévia provocação e manifestação dos interessados na construção da decisão final.

Por meio da jurisdição, estabelece-se a competência, que delimita o poder ou a atribuição ${ }^{1}$ das autoridades, em virtude da matéria envolvida, considerando-se o território onde a decisão deva ser proferida. De maneira que De Plácido e Silva (1998a) explicita que jurisdição é o gênero que aparece primeiramente, outorgando o poder à autoridade, enquanto a competência é espécie e pressuposto da jurisdição, restringindo a atribuição da última. Nesse sentido, segundo José Afonso da Silva (1995, p. 455)
${ }^{1}$ Expressões empregadas, neste trabalho, como sinônimas. 
"competência é a faculdade juridicamente atribuída a uma entidade, ou a um órgão ou agente do Poder Público para emitir decisões. Competências são as diversas modalidades de poder de que se servem os órgãos ou entidades estatais para realizar suas funções".

Para Ranieri, no Estado Federal brasileiro, as regras que estabelecem as competências públicas envolvem diversos poderes e entes federados, para cumprir com suas responsabilidades, na maneira apresentada pela CR/88. ${ }^{2}$ Dessa forma, a competência pública é questão fundamental, pois se vincula à criação de

[...] um governo compatível com as exigências e necessidades da União, além de influir diretamente no equilíbrio do pacto federativo, determinando o grau de tensão entre o poder central e as unidades periféricas, no que diz respeito a descentralização e controle (aspectos fundamentais na área da educação em face das disposições da Lei no 9.394/96). (Ranieri, 2000, p. 92-93).

Assim, estabelece-se uma relação inversamente proporcional entre as competências dos poderes central e periféricos: quanto maior as atribuições da Administração Pública central, maior o nível de centralização, e, por consequência, menor parcela de poder caberá aos Poderes Públicos locais; contrariamente, quanto maior a descentralização, o ente central possuirá menor parcela de competência, reservando-se aos órgãos periféricos maiores atribuições. Com isso, "a idéia subjacente é permitir que os dois níveis de estatalidade, o central e os periféricos, funcionem autônoma e concomitantemente" (Ranieri, 2000, p. 93).

Segundo José Afonso da Silva (1995), a CR/88 emprega um sistema complexo de repartição de competências, para alcançar o equilíbrio federativo. Emprega uma técnica que busca, primeiramente, a enumeração dos poderes da União (CR/88, arts. 21 e 22), concedendo poderes remanescentes aos Estados e ao Distrito Federal (CR/88, art. 25, § $\left.1^{\circ}\right)$, e, ainda, indica atribuições aos Municípios (CR/88, art. 30). Além disso e sem prejuízo da reserva de campos específicos (privativos, mas nem sempre exclusivos), compatibiliza a possibilidade de delegação (CR/88, art. 22, parágrafo único) de áreas comuns, com admissão de ações paralelas de todos os entes federados (CR/88, art. 23), e de segmentos concorrentes entre a União e os Estados membros, como, por exemplo, a competência da União para instituir políticas gerais, diretrizes gerais e normas gerais (CR/88, arts. 21, incisos XIX, XX e XXI, 22, incisos IX, XXI e XXIV, e 24, § $\left.1^{\circ}\right)$, enquanto atribui aos Estados e, às vezes, aos Municípios competência suplementar (CR/88, art. 30, inciso II).

Resulta, então, a classificação de competência quanto à extensão, ou seja, quando existe a possibilidade de um ou mais órgãos sugerirem a aprovação de leis (proposta de normatividade). ${ }^{3}$ Distingue-se em:

(a) exclusiva, quando é atribuída a uma entidade com exclusão das demais (art. 21);

(b) privativa, quando enumerada como própria de uma entidade, com possibilidade, no entanto, de delegação e de competência

\footnotetext{
${ }^{2}$ O constitucionalismo português defende que "o princípio da competência diz-nos que os órgãos em certo momento competentes para a emissão de actos legislativos não o podem deixar de ser por simples vontade sua, ou através de um mecanismo de delegação. As alterações de competência têm de estar previstas constitucionalmente e não são permitidas vicissitudes de competência fora dessas condições" (Gouveia, 2005b, p. 1226; no mesmo sentido, Miranda, 2000, p. 54-60).

${ }^{3}$ Da mesma maneira, a doutrina portuguesa apresenta diversos critérios que identificam as modalidades de competência legislativa, entre elas o critério da atribuição exclusiva ou concorrente, com suas competências legislativas exclusiva, delegável e concorrente. Trata-se de formas de distribuição horizontal da função de legiferação, ocorrendo no âmago de cada pessoa coletiva com poder normativo (Gouveia, 2005b, p. 1230-1233; em sentido equivalente, ao analisa as competências legislativas reservadas, absoluta e relativa, e a concorrencial, Miranda, 2000 p. 225-226).
} 
suplementar (art. 22 e seu parágrafo único, e art. 23 e seus parágrafos); a diferença entre a exclusiva e privativa está nisso, aquela não admite suplementariedade nem delegação;

(c) comum, cumulativa ou paralela, reputadas expressões sinônimas, que significa a faculdade de legislar ou praticar certos atos, em determinada esfera, juntamente e em pé de igualdade, consistindo, pois, num campo de atuação comum às várias entidades, sem que o exercício de uma venha a excluir a competência de outra, que pode assim ser exercida cumulativamente (art. 23);

(d) concorrente, cujo conceito compreende dois elementos:

(d.1) possibilidade de disposição sobre o mesmo assunto ou matéria por mais de uma entidade federativa;

(d.2) primazia da União no que tange à fixação de normas gerais (art. 23 e seus parágrafos);

(e) suplementar, que é correlativa da competência concorrente, e significa o poder de formular normas que desdobrem o conteúdo de princípios ou normas gerais ou que supram a ausência ou omissão destas (art. 23, §§ $1^{\circ}$ a $4^{\circ}$ ). (Silva, J. A. 1995, p. 457).

A competência concorrente (CR/88, art. 24) pode apresentar problemas de interpretação, posto que as normas indicam parâmetros de acumulação ou não. Desse modo, a técnica cumulativa autoriza que as entidades federadas disciplinem, ilimitada e normativamente, determinadas matérias, condicionando tal atividade à abstenção do ente central. Não obstante, a técnica não cumulativa assegura à entidade central competência uniformizadora de certa matéria, permitindo, simultaneamente, aos demais entes federados, atribuição suplementar, para adequar diretrizes, bases e fundamentos da referida uniformização à sua idiossincrasia. Ranieri (2000) leciona que a maior parcela de competência do Governo Federal aumenta a tendência compensatória de se elevar as competências concorrentes dos Estados membros, do Distrito Federal e dos Municípios, de maneira que se trata de técnica compatível com o sistema federativo, já que, sem prejuízo do ordenamento nacional, abre-se a possibilidade de respeito e de adaptação às características locais ante o princípio de subsidiariedade. Nesse sentido,

\footnotetext{
Cogita-se, na formulação do princípio de subsidiariedade, do equilíbrio entre o poder central e o poder local. A idéia concretiza-se na compreensão da absorção da substância local e da vitalidade local pelo poder central. O poder local deve dispor de condições que crie situações para a formação do cidadão e do Município. A repartição de competências vincula-se à compreensão do princípio de subsidiariedade, pelo que o Estado deve transferir ou delegar às coletividades os poderes que têm a capacidade de exercer. (Baracho, 2000, p. 32).
}

Ainda para Ranieri (2000, p. 94-95), o sistema estabelecido pela CR/88, para se fixar as atribuições, contribui para a centralização das competências concorrentes, "apontando para um federalismo cooperativo mais preocupado com a colaboração dos entes federados do que com a sua separação e independência recíprocas". Com isso, a coordenação de políticas 
públicas é extremamente importante, tanto quanto a uniformização de interesses, para que o federalismo cooperativo possa separar questões locais das matérias que são inerentes a todos os órgãos periféricos, recebendo a qualidade nacional de norma geral e principiológica. A repartição de competências, em níveis genéricos, entre a União e os Estados membros, inclusive o Distrito Federal, comprova a conexão entre o princípio da subsidiariedade e o federalismo cooperativo.

Portanto, a CR/88 desejou o estabelecimento de um pacto federativo cooperativo e integrador, para conceder autonomia às entidades federadas, acercando a Administração Pública dos cidadãos, em suas regiões e localidades.

\section{Competência em matéria educacional, na CR/88}

No âmbito educacional brasileiro, a repartição de competências materiais demonstra atribuições concorrentes e descentralizadoras, objetivando uma cooperação recíproca entre os entes federados, cada qual em sua área específica de execução, principalmente no oferecimento da educação básica. Existe uma compatibilização entre competências privativas e comuns para nortear as políticas públicas educacionais. Assim, a União aparece, em nível hierarquicamente superior, na edição de normas gerais educacionais, em todos os níveis, tendo atuação coordenadora, supletiva e redistributiva em todo o sistema nacional. No ensino superior, o Governo Federal atua com prevalência relativa nos níveis de competência, obrigações e gestão de todo o sistema.

Conforme Ranieri (2000), nos dispositivos constitucionais relativos à educação é clara a determinação de estabelecimento de um Estado Social, segundo o qual se reconhece a existência de desigualdades e fornecem-se meios para sua solução. Com isso, o art. 205 da CR/88 define responsabilidade comum às pessoas jurídicas de direito público interno brasileiras, o que é respaldado pelo art. 208, caput.

No art. 211 e seus $\S \S$, a CR/88, como norma de princípio programático endereçada ao Poder Público, estabelece as competências materiais de cada esfera governamental:

Art. 211. A União, os Estados, o Distrito Federal e os Municípios organizarão em regime de colaboração seus sistemas de ensino.

$\S 1^{\circ}$ A União organizará o sistema federal de ensino e o dos Territórios, financiará as instituições de ensino públicas federais e exercerá, em matéria educacional, função redistributiva e supletiva, de forma a garantir equalização de oportunidades educacionais e padrão mínimo de qualidade do ensino mediante assistência técnica e financeira aos Estados, ao Distrito Federal e aos Municípios.

$\S 2^{\circ}$ Os Municípios atuarão prioritariamente no ensino fundamental e na educação infantil.

$\S 3^{\circ}$ Os Estados e o Distrito Federal atuarão prioritariamente no ensino fundamental e médio. 
${ }^{4}$ Art. $3^{\circ}$ da Lei $n^{\circ} 11.274$, de 6 de fevereiro de 2006, que altera, entre outros, o art. 32 da LDB: "O ensino fundamental obrigatório, com duração de 9 (nove) anos, gratuito na escola pública, iniciando-se aos 6 (seis) anos de idade, terá por objetivo a formação básica do cidadão, mediante: [...]."
$\S 4^{\circ} \mathrm{Na}$ organização de seus sistemas de ensino, a União, os Estados, o Distrito Federal e os Municípios definirão formas de colaboração, de modo a assegurar a universalização do ensino obrigatório.

$\S 5^{\circ}$ A educação básica pública atenderá prioritariamente ao ensino regular.

Ranieri (2000) explicita que o ponto de partida é a competência comum, para, a partir de tal atribuição, indicar-se a atuação prioritária, não exclusiva, dos entes federados, com relação aos níveis de ensino, ressalvada a União, que deverá organizar os sistemas educacionais de forma colaborativa, com base na regulamentação estatuída pelos arts. $8^{\circ}$ a 11 da Lei de Diretrizes e Bases da Educação Nacional (LDB) - Lei no 9.394, de 20 de dezembro de 1996. O regime de colaboração é salientado no art. 211, § $4^{\circ}$, da CR/88, com o fim de garantir a universalização do ensino fundamental obrigatório (CR/88, art. 208, inciso I). ${ }^{4}$

Em complementação ao conceito apresentado anteriormente (Silva, J. A. 1995, p. 457), a finalidade das "competências comuns é a difusão dos interesses que se encontram subjacentes e que determinam um condomínio de atuações. Nenhuma das entidades é titular exclusiva, superior ou desigual das competências. Não se dá aqui nem superioridade hierárquica nem subordinação de uma das entidades. Não se dá a exclusividade da responsabilidade de uma delas nem (e muito menos) a omissão possível dessa responsabilidade por qualquer delas. A execução das competências comuns pode ser pleiteada de todas as entidades. A forma de cooperação para que ela se faça de forma eficiente é que se impõe na forma determinada pela lei complementar prevista no parágrafo único do art. 23 da Constituição" (Rocha, 1997, p. 253).

De maneira que as competências das entidades federadas podem ser explicitadas como se segue, no que tange à educação formal:

Cabe à União, exclusivamente, "elaborar e executar planos nacionais e regionais de ordenação do território e de desenvolvimento econômico e social" (CR/88, art. 21, inciso IX). Ademais, a União intervirá nos Estados e no Distrito Federal para assegurar o cumprimento do princípio constitucional de aplicação do mínimo exigido da receita de impostos estaduais, inclusive de transferências tributárias, na manutenção e no desenvolvimento do ensino (CR/88, art. 34, inciso VII, alínea "e"). Organizará, ainda e em regime de colaboração, os sistemas de ensino, financiando as instituições de educação públicas federais e exercendo, "em matéria educacional, função redistributiva e supletiva, de forma a garantir equalização de oportunidades educacionais e padrão mínimo de qualidade do ensino mediante assistência técnica e financeira aos" outros entes federados (CR/88, art. 211 e seu $\left.\S 1^{\circ}\right)$. Além disso, "aplicará, anualmente, nunca menos de dezoito (por cento) [...] da receita resultante de impostos, compreendida a proveniente de transferências, na manutenção e desenvolvimento do ensino" (CR/88, 
art. 212). Por fim, garantirá o padrão mínimo de qualidade (CR/88, art. 206, inciso VII), em todos os níveis e categorias administrativas, procedendo à autorização e avaliação qualitativa na iniciativa privada (CR/88, art. 209, inciso II).

\section{Regulamentação infraconstitucional}

Por sua vez, o Governo Federal coordenará a política nacional educacional, articulando os sistemas de ensino e os respectivos níveis básico e superior, conforme os arts. $8^{\circ}$ e $9^{\circ}$ da LDB. De forma que o art. $8^{\circ}$ da LDB regulamentou os $\S \S 2^{\circ}$ e $3^{\circ}$ do art. 211 da CR/88 e autorizou a União a coordenar as entidades federativas que poderão fornecer educações básica e superior, desde que os Estados, inclusive o Distrito Federal, atuem, prioritariamente, nos ensinos fundamental e médio e os Municípios no fundamental e na educação infantil, do mesmo modo. Como a CR/88 não previu atuação prioritária do Governo Federal, constata-se, por sua parte, a necessidade de emissão de políticas públicas redistributivas e supletivas em todos os níveis de ensino, sem prejuízo da atenção a ser dispensada à educação superior, ante a omissão constitucional quanto à participação dos Estados membros e Municípios no seu fornecimento. Portanto e com referência ao ensino superior, a atuação da União é residual, já que tal atribuição não aparece como função primordial das demais entidades federadas, e supletiva, porque, por força do art. $211, \S 1^{\circ}$, da CR/88, deve-se somar ao sistema educacional como um todo, para aperfeiçoá-lo e ampliá-lo, suprindo eventuais faltas, apesar de não se estimular a oferta deste nível de ensino pelos Estados e Municípios, a teor do art. 16 da LDB.

Art. 16 - O sistema federal de ensino compreende:

I - as instituições de ensino mantidas pela União;

II - as instituições de educação superior criadas e mantidas pela iniciativa privada;

III - os órgãos federais de educação. (Brasil. Lei no 9.394, 1996).

Cabe aos Estados, ao Distrito Federal e aos Municípios a execução dos planos nacional e estadual de educação, tendo em vista o dever constante nos arts. 205 da CR/88 e 10 e 11 da LDB. Ademais, deverão aplicar, anualmente, 25\% (vinte e cinco por cento), "no mínimo, da receita resultante de impostos, compreendida a proveniente de transferências, na manutenção e desenvolvimento do ensino" (CR/88, art. 212). Finalmente, assegurarão o padrão mínimo de qualidade (CR/88, art. 206, inciso VII), procedendo à autorização e à avaliação de qualidade no âmbito de seus sistemas de ensino, inclusive do segmento particular (CR/88, art. 209, inciso II).

Ressalte-se que o ensino ambiental ${ }^{5}$ é atribuição de todos os entes federados, em todos os níveis, por não constar na seção específica da educação, nos termos do art. 225, § 1º, inciso VI, da CR/88.
${ }^{5}$ Considerado como um tipo de educação não formal e informal (Ranieri, 2000, p. 100). 


\section{Competência legislativa educacional}

Nesse contexto, surge o primeiro problema relacionado com a competência legislativa educacional, repartida entre os entes federados. O dilema diz respeito à manutenção das autonomias normativas regionais, porque existe uma confusão no Congresso Nacional sobre "as atribuições de editar a lei de diretrizes e bases, as normas gerais de educação e a lei federal ordinária, ante sua dupla qualidade de legislativo nacional e legislativo federal" (Ranieri, 2000, p. 90). ${ }^{6}$ Apesar da notória distinção entre tais comandos normativos, "o fato de emanarem do mesmo órgão legislativo e o de originarem-se por processos semelhantes dificultam o seu discernimento, com prejuízo para os Estados, que acabam por não exercer competências legislativas próprias" (Ranieri, 2000, p. 90), deixando sem regulamentação seus sistemas de ensino. Portanto, o problema acaba por se tornar mais grave, à medida que a diferença, em razão da matéria, entre a lei de diretrizes e bases e as normas gerais de educação é quase imperceptível, pois ambas são genéricas e vigem em todo o território nacional. Assim, Ranieri (2000) explica que de tal distinção surge a competência suplementar dos Estados e do Distrito Federal para legislar, atendendo às próprias peculiaridades $\left(\mathrm{CR} / 88\right.$, art. $24, \S \S 1^{\circ}, 2^{\circ}$ e $3^{\circ}$ ). Para solucionar tal dilema, é preciso explicitar as competências legislativas dos entes federados.

Como já mencionado anteriormente, o Governo Federal possui função supletiva e residual em suas responsabilidades para com a educação. Contrariamente, no plano legislativo indicam-se expressamente suas atribuições. Nesse sentido, "compete privativamente à União legislar sobre diretrizes e bases da educação nacional" (CR/88, art. 22, inciso XXIV), enquanto também compete aos Estados membros, incluído o Distrito Federal, "legislar concorrentemente sobre educação, cultura, ensino e desporto" (CR/88, art. 24, inciso IX).

Conforme os $\S \S 1^{\circ}, 2^{\circ}, 3^{\circ}$ e $4^{\circ}$ do art. 24 da $C R / 88$ e no que toca à legislação concorrente, a atribuição da União é limitada ao estabelecimento de normas gerais, o que não exclui a competência suplementar dos Estados

${ }^{6}$ Em sentido equivalente sobre membros, de maneira que, se não existir lei federal sobre tais normas, os Estados exercerão a competência legislativa plena, a fim de atender suas peculiaridades. Caso venha a ser editada lei federal posterior sobre normas gerais, a lei estadual terá a sua eficácia suspensa no que lhe for oposto. Desse modo, a competência legislativa dos Estados e Municípios é remanescente e, por tal motivo, restrita. Reitera-se, então, que à União cabe editar normas gerais educacionais, enquanto aos Estados compete a proposta de normas suplementares. Na hipótese de inexistência de normas gerais, os últimos detêm capacidade legislativa plena, na qualidade de competência supletiva, ${ }^{7}$ até a superveniência de lei federal, que suspenderá a eficácia da estadual no que lhe for incompatível.

Por sua vez, o $§ 1^{\circ}$ do art. 25 da CR/88 reserva aos Estados membros e ao Distrito Federal as competências não proibidas por ela, entre as quais a possibilidade de aprovar normas suplementares e peculiares 
ao seu sistema educacional. Da mesma forma, os Municípios podem "legislar sobre assuntos de interesse local" (CR/88, art. 30, inciso I), baixando "normas complementares para o seu sistema de ensino" (Lei no 9.394/96, art. 11, inciso III). Inexiste possibilidade de suplementação de legislação federal e estadual pela municipal em questões inerentes à educação (CR/88, art. 30, inciso II), já que a competência concorrente do art. 24, caput, da CR/88 somente cabe à União, aos Estados e ao Distrito Federal. ${ }^{8}$ Em resumo:

O âmbito da legislação federal é estabelecido pelos amplos e vagos encargos que podem decorrer de ações supletivas e redistributivas; os seus limites, pelas competências estaduais e municipais, na forma compatibilizada pela opção federativa, sendo este o aspecto fundamental a ser ressaltado. É dizer, nem as normas gerais nem a lei de diretrizes e bases podem invadir a esfera própria das demais pessoas políticas, nem versar sobre matéria alheia aos encargos atribuídos à União, sob pena de incompetência absoluta. Outra não é a conclusão que se extrai de nosso sistema constitucional e do conceito jurídico de "competência pública" [...] (Ranieri, 2000, p. 101).

Dessa maneira, a aplicabilidade e a interpretação, por parte dos entes federados, das normas nacionais que tratam de matérias genéricas não derivam de qualquer parâmetro hierárquico, mas do próprio regime federativo e das normas constantes na $\mathrm{CR} / 88$. Assim, não há hierarquia entre normas gerais de educação, LDB e normas suplementares dos Estados; o que existe, verdadeiramente, é uma eficaz coordenação do interesse nacional, uma aplicação efetiva da repartição de competências. ${ }^{9}$

Na lição de José Afonso da Silva (1995), o princípio que orienta a repartição de competências entre as entidades federadas é o chamado de predominância do interesse. Por tal princípio, caberão à União as questões de predominante interesse nacional ou geral; aos Estados membros e ao Distrito Federal, as matérias de predominante interesse regional; e aos Municípios, os assuntos de predominante interesse local. Portanto, mesmo diante de uma previsão legislativa em matéria de educação, diferenciam-se normas supletivas de normas gerais e ambas, da lei de diretrizes e bases, por meio de um critério de exclusão, isto é, aufere-se se a norma especializa e individualiza questões peculiares, indicando, ainda, a extensão territorial da sua aplicabilidade. Caso o faça, será norma suplementar, específica e, consequentemente, de competência estadual; em sentido oposto, na hipótese de não especializar a matéria, mas fixar fundamentos e princípios, acabará por receber tratamento generalizador, de fundo nacional, o que é inerente às normas gerais e à lei de diretrizes e bases.

Dito isso, torna-se necessário distinguir a lei de diretrizes e bases das normas gerais de educação. A matéria relacionada com as diretrizes e bases é mais exata, na medida em que seu conteúdo vincula-se aos princípios, fundamentos/motivos, estrutura organizacional e parâmetros de exequibilidade da educação escolar, não sendo uma simples análise sobre a generalidade da norma.
${ }^{8}$ Segundo a doutrina jurídica, a "competência não se presume; entretanto, uma vez assegurada entende-se conferida com a amplitude necessária para o exercício do poder ou desempenho da função a que se refere a lei" (Maximiliano, 1998, p. 265).

${ }^{9}$ Ao compartilhar tal conclusão, o Parecer CNE/CEB (Câmara de Educação Básica) no 30, de 12 de setembro de 2000, ainda explica que: "[...] a lógica do modelo constitucional vigente $e$ da LDB presumem a inexistência de incompatibilidades reais ou supostas, seja pela repartição de atribuições, seja pelo princípio de colaboração, seja pelas finalidades comuns. Qualquer invasão de competências toma, então, um caráter anticonstitucional" (Brasil. CNE, 2000, p. 28; no mesmo sentido, Boaventura, 1997, p. 191-275). 
Desse modo, para Ranieri (2000, p. 108), "o vocábulo 'diretriz' tem o sentido de 'opção de mérito'" e, na área educacional, relaciona-se com a "promoção do indivíduo como pessoa, cidadão e trabalhador [...], cuja execução requer condições de exequibilidade (órgãos, autoridades, meios de concretização)", cumprindo os preceitos do art. $3^{\circ}$ da CR/88, os princípios educacionais (CR/88, arts. 206, incisos I e IV, 208, inciso VI, e 211) e constituindo uma "base", propriamente dita. Além disso, é fundamento do sistema brasileiro "a indicação da preeminência do Ministério da Educação e do Conselho Nacional de Educação como órgãos definidores das políticas públicas para os diversos graus de ensino (cf. Lei no 9.131, de 24.11 .95 [...])" (Ranieri, 2000, p. 108).

Por força do art. 22, inciso XXIV, da CR/88, a LDB - Lei nº 9.394/96 - é nacional, regula todos os sistemas de ensino e, "por ser norma fundamental, diretriz, não tem a natureza de legislação exaustiva" (Ranieri, 2000, p. 109). Em sentido equivalente, "o Congresso Nacional dá as diretrizes e bases da educação nacional. Não pode fazer legislação exaustiva. Se o faz, infringe a Constituição de 1967. A legislação estadual é que há de ir no sentido do que se lhe traçou" (Pontes de Miranda, 1968, p. 343-344).

De forma mais explicativa:

\begin{abstract}
A legislação concorrente da União sobre as matérias indicadas supra se limitará a estabelecer normas gerais. Nisso a Constituição foi, às vezes, redundante. Por exemplo, no art. 22, XXIV, dá como privativo da União legislar sobre diretrizes e bases da educação nacional, enquanto, no art. 24, IX, combinado com o § $1^{\circ}$, declara caber-lhe legislar sobre normas gerais de educação. Não há nisso incoerência, como pode parecer. Legislar sobre diretrizes e bases da educação nacional e sobre normas gerais de educação somam, no fundo, a mesma coisa. A tradição arrastou os educadores da Constituinte a manter a regra que vem de 1946, que dava competência à União para legislar sobre diretrizes e bases da educação nacional, mas também não poderiam deixar de incluir na competência comum legislar sobre educação, situação em que a União só tem poderes para fixar normas gerais. Tudo somado, dá na mesma, com um dispositivo a mais sem necessidade. [...] nos termos do $\S 2^{\circ}$ do art. 24, a competência da União para legislar sobre normas gerais não exclui (na verdade até pressupõe) a competência suplementar dos Estados (e também do Distrito Federal, embora não se diga aí), e isso abrange não apenas as normas gerais referidas no $\S 1^{\circ}$ desse mesmo artigo no tocante à matéria neste relacionada, mas também as normas gerais indicadas em outros dispositivos constitucionais, porque justamente a característica da legislação principiológica (normas gerais, diretrizes, bases), na repartição de competências federativas, consiste em sua correlação com competência suplementar (complementar e supletiva) dos Estados.
\end{abstract}

Tanto isso é uma técnica de repartição de competência federativa que os $\S \S 3^{\circ}$ e $4^{\circ}$ complementam sua normatividade, estabelecendo, em primeiro lugar, que, inexistindo lei federal sobre normas gerais, os Estados exercerão a competência legislativa plena, para atender a suas peculiaridades, e, em segundo lugar, que a superveniência de lei federal sobre normas gerais suspende a eficácia da lei estadual, no que lhe for contrária. Note-se bem, o constituinte foi técnico: a lei federal superveniente não revoga a lei estadual nem a derroga no aspecto contraditório, esta apenas perde sua aplicabilidade, por ficar com sua eficácia suspensa. Quer dizer, também, sendo revogada a lei federal pura e simplesmente, a lei estadual recobra sua eficácia e passa outra vez a incidir (Silva, J. A. 1995, p. 477-478). 
O simples fato de constar no art. 22, inciso XXIV, da CR/88 a competência da União para legislar sobre diretrizes e bases educacionais não exclui a atribuição estadual para normalizar, de modo suplementar, a matéria, nos termos do $\S 2^{\circ}$ do art. 24 da CR/88, pois ao ente central cabe editar apenas normas gerais $\left(\mathrm{CR} / 88\right.$, art. $\left.24, \S 1^{\circ}\right)$, enquanto entidades estaduais, em caráter suplementar, podem legislar normas específicas, para atenderem suas particularidades. A natureza principiológica, diretiva, geral ou basilar da matéria "será disciplinada genericamente pela União e suplementada pelos Estados, [havendo] pontos que não serão objeto de tratamento uniforme no âmbito nacional, por atenderem a interesses predominantemente estaduais ou locais" (Ranieri, 2000, p. 117), ou seja, peculiares. Por isso, não existe hierarquia entre as leis educacionais brasileiras, demonstrando a vigência plena dos comandos constitucionais que instituem a repartição de competências por colaboração recíproca, segundo o art. 211 da CR/88.

Com isso, Ranieri (2000, p. 112) pensa que, na prática e com referência à educação, não haverá aplicação do parágrafo único do art. 22 da $\mathrm{CR} / 88^{10}$ a favor dos Estados, pois a União não possui "competência privativa plena, mas, tão-somente, a competência concorrente, limitada", contingenciamento também verificado na organização dos sistemas de ensino brasileiros e nos comandos do art. 214 da CR/88 e do Plano Nacional de Educação (PNE), Lei Federal no 10.172/01. Portanto, a mesma doutrinadora apresenta dois casos de aplicação errada da LDB, por parte do Governo Federal, em detrimento da autonomia dos Estados membros. O primeiro, o episódio da determinação do Ministério da Educação (MEC), por meio de sua Secretaria de Educação Superior (SESu), de se avaliar o curso de Direito da Universidade de São Paulo (USP), ante o art. 46 da LDB e o Ofício Circular no 040/98 - Gab/SESu/MEC. O equívoco consistia na desatenção sobre os arts. 9, inciso IX, e 16, ambos da LDB, e 209, inciso II, da CR/88, já que a União somente pode avaliar cursos de Instituições de Ensino Superior (IES) de seu sistema de ensino, isto é, instituições federais e particulares. A avaliação do curso de Direito da USP deveria ser feita pelo Estado de São Paulo e pela própria USP, sob pena de dispêndio reiterado de recursos públicos estaduais, ressalvada a cooperação entre os sistemas, se assim o quiserem, nos termos do art. 9 ${ }^{\circ}$ inciso VIII, da LDB. O segundo, a composição dos colegiados das universidades públicas estaduais, tendo em vista a proporção determinada pelo parágrafo único do art. 56 da LDB, em oposição aos arts. 207 da CR/88 (norma coercitiva e de eficácia plena) e 254, inciso II, da Constituição Estadual de São Paulo, já que se trata de questão de interesse peculiar do mencionado ente federado, "protegida pela vertente administrativa da autonomia universitária", e o dispositivo da LDB "não tem conteúdo diretivo basilar" (Ranieri, 2000, p. 115-116).

Não obstante, só assiste razão a Ranieri no primeiro exemplo, sendo indispensável uma modificação na LDB, a fim de inserir no sistema federal de ensino todas as instituições de ensino superior, inclusive as estaduais e municipais. ${ }^{11}$ Com relação à citada segunda hipótese, entende-se que
${ }^{10}$ Art. 22 - Compete privativamente à União legislar sobre: [...] Parágrafo único. Lei complementar poderá autorizar os Estados a legislar sobre questões específicas das matérias relacionadas neste artigo (Brasil. Constituição... 1988).

11 Saliente-se que existem opiniões completamente opostas, desejando a inserção das IES privadas nos sistemas estaduais de ensino, o que não procede, em virtude das melhores condições estruturais e do maior conhecimento técnico existentes na SESu/MEC, como será posteriormente desenvolvido neste trabalho. 
a autonomia universitária, apesar de deter conteúdo autoaplicável, não incide sobre a gestão democrática do ensino público, também prevista na CR/88, em seu art. 206, inciso VI. A proporção indicada no parágrafo único do art. 56 da LDB é sim norma principiológica e basilar, dirigindo e outorgando aplicabilidade ao referido princípio constitucional da gestão democrática em qualquer categoria administrativa. Agora, se os estatutos universitários das universidades públicas paulistas não respeitam a diretriz da LDB devem a ela se adequar, de modo a congregar segmentos da comunidade regional, local e institucional, sem prejuízo da ocupação de 70\% (setenta por cento) dos assentos nos respectivos órgãos colegiados e comissões garantida aos docentes.

Cabe salientar que esta parte deste artigo demonstrou uma pretensão do constituinte em determinar a composição e a cooperação entre a União, os Estados, o Distrito Federal e os Municípios, "mediante técnicas de competências concorrentes e redefinição de competências comuns" (Ranieri, 2000, p. 125), para evitar o excesso de atribuições do ente central, ainda que suas competências sejam demasiado amplas e abrangentes.

\section{Sistemas de ensino}

Segundo De Plácido e Silva (1998b, p. 761), sistema advém do grego systema, apresentando "sentido de reunião, método, juntura" e exprimindo "o conjunto de regras e princípios sobre uma matéria, tendo relações entre si, formando um corpo de doutrinas e contribuindo para a realização de um fim. É o regime a que se subordinam as coisas. Assim, todo conjunto de regras, que se devem aplicar na ordenação de certos fatos, integrantes de certa matéria, constitui um sistema".

Em sentido equivalente, sistema é, segundo Canotilho (1993, p. 45),

um conjunto de elementos em interacção, organizado em totalidade, que reage às interacções de tal forma que, quer ao nível dos elementos constitutivos quer ao nível do conjunto, aparecem fenómenos e qualidades novas não reconduzíveis aos elementos isolados ou à sua simples soma.

Assim, segundo Ranieri (2000, p. 117), "um sistema, portanto, racionaliza e organiza vários elementos que operam em sinergia para alcançar determinado objetivo, conferindo-lhes unidade". Ranieri acredita que, em matéria educacional, o sistema é composto pelo conjunto de instituições, com seus elementos materiais e pessoais, e pelo ordenamento jurídico federal e estadual, o que se denomina sistema de ensino ou sistema de educação.

De fato, verifica-se a participação efetiva da Administração Pública, por meio predominante das normas de competência acima declinadas e dos atos administrativos normativos, inclusive dos Conselhos de Educação, na organização dos elementos materiais ou não, atrelados à educação, formando um conjunto sistêmico, também chamado de sistema de ensino. 
Em consequência do conceito supracitado, Ferraz (1976) sintetiza seus componentes ${ }^{12}$ empregando a filosofia aristotélico-tomista: os recursos, pessoas e objetos, como a matéria que compõe o sistema; o ordenamento jurídico que atribui forma ao sistema, compreendendo-se as leis e os atos administrativos normativos; o órgão da Administração Pública, para outorgar organização ao sistema; e os valores éticos, políticos, econômicos, religiosos e pedagógicos sobre os quais se estrutura o mesmo sistema. Conclui que o ordenamento brasileiro, seja constitucional ou infraconstitucional, utiliza a expressão sistema de educação para descrever a estrutura organizada pela União (sistema federal de ensino) e pelos outros entes federados (sistemas estaduais e locais) para suprir as suas demandas educacionais.

Com efeito, a organização brasileira dos sistemas de ensino deriva da estrutura político-administrativa da República Federativa do Brasil, a teor do art. 18, caput, da CR/88, "aplicando-se-lhe por simetria o princípio federativo da descentralização normativa e executiva" (Ranieri, 2000, p. 120).

De maneira que a atuação da União, em matéria de princípios e condutas gerais, não poderá retirar as atribuições específicas dos Estados e Municípios (organizar e gerir os seus sistemas de ensino, conforme o art. 211 da CR/88), na qualidade de entidades autônomas (não por delegação), para atenderem às suas peculiaridades regionais e locais, respectivamente, tudo isso sob pena de não se formar um sistema nacional de ensino e de enfraquecer a própria Federação brasileira, baseada na descentralização política e administrativa na educação, a exemplo do que ocorre com a competência legislativa suplementar. Cabe destacar que as decisões e ações dos entes políticos periféricos não podem conflitar com as diretrizes e bases instituídas pela entidade central, tendo em vista a sua qualidade de legislação federal principiológica, o que não impede a premente atividade dos primeiros.

Ranieri (2000, p. 123) pensa que o tema da existência de um sistema nacional de ensino está atrelado aos objetivos do Estado e não à partilha do poder, e, mediante a análise de seu conceito de sistema, declara parecer evidente que ele se constitui "pelos sistemas federal, estaduais, municipais e do Distrito Federal, de natureza antes sociológica que legal, mas de expressão constitucional". Assim, prossegue explicitando que o sistema nacional seria um "sistema independente", desejando, a partir do ordenamento jurídico educacional editado por todas as pessoas políticas brasileiras, "concatenar os objetivos nacionais por intermédio de análise das relações que ali surgem e se produzem, e cuja expressão se torna mais evidente em razão da previsão do Plano Nacional de Educação" (p. 123-124), previsto no art. 214 da CR/88.

Consequentemente, inexiste subordinação entre os sistemas educacionais brasileiros, pois houve uma divisão das competências constitucionais na matéria em questão, ressalvada a hipótese de a União legislar, com finalidade organizacional e para a Nação, sobre diretrizes e normas gerais da educação. Portanto, o referido sistema nacional não é superior, hierarquicamente, aos outros, mas se orienta pela $\mathrm{CR} / 88$, pela
${ }^{12}$ Leia-se elementos essenciais. 
LDB e pelo PNE, isto é, toda e qualquer política pública deverá respeitar os princípios e o planejamento nacional instituído por tais normas.

Sem embargo, a LDB regulamentou em nível basilar o art. 211 da $\mathrm{CR} / 88$, estabelecendo a composição de todos os sistemas de ensino. Desse modo e como apresentado anteriormente, o sistema federal é formado pelas instituições de ensino, de qualquer nível, providas financeiramente pela União, pelas IES criadas e mantidas pelo setor privado e pelos órgãos federais de educação (LDB, art. 16). Por sua vez, os sistemas de educação dos Estados membros são compostos por todas as instituições de ensino mantidas, respectivamente, pelas administrações públicas estaduais e pelo Distrito Federal, pelas IES financiadas pelos Municípios, pelas instituições de ensino fundamental e médio do segmento particular e pelos órgãos de educação estaduais e do Distrito Federal (LDB, art. 17). Já os sistemas municipais compreendem as instituições do ensino fundamental, médio e de educação infantil mantidas pelas administrações públicas municipais, pelas instituições de educação infantil originadas e sustentadas pela iniciativa privada e pelos órgãos de ensino municipais (LDB, art. 18). Ressalte-se a viabilidade, já mencionada, de inserção dos Municípios no sistema educacional dos Estados membros ou, ainda, de composição conjunta de um sistema único de educação básica (LDB, art. 11, parágrafo único).

Em resumo, a União só pode atuar de forma ampla em conformidade com a finalidade estratégica nacional e os princípios constitucionais educacionais. Por outro lado, os órgãos periféricos da Federação podem e devem se organizar internamente, mediante a aprovação de leis e a expedição de atos administrativos (em sentido amplo e não apenas os normativos), desde que o façam para atingir suas localidades, no âmbito de suas competências. Além disso, todas as entidades federadas devem estar integradas e devem funcionar em regime de cooperação, impedindo a separação dos sistemas de ensino, eventuais privilégios, dependências institucionais e dispêndio de recursos econômicos.

\section{Competências e atribuições específicas na LDB}

Como salientado e em reforço às normas constitucionais (CR/88, arts. 22, inciso XXIV, 24, inciso IX, e 211, § $1^{\circ}$ ), os arts. $8^{\circ}$ e $9^{\circ}$ da LDB determinam que a União é competente para coordenar a política nacional educacional, mediante articulação entre os distintos níveis e sistemas, exercitando funções normativas de maneira redistributiva e supletiva aos demais entes federados.

Os incisos do art. $9^{\circ}$ da LDB apresentam os encargos específicos da referida coordenação política e estabelecem o sistema federal, demonstrando a necessária articulação entre os diferentes níveis e sistemas de ensino, em conformidade com as metas e objetivos estabelecidos no PNE (CR/88, art. 214, e Lei no 10.172/01), de forma a integrar o Poder Público em todas as suas esferas administrativas. Com relação às funções normativas, os atos do Governo Federal, quando se tratar de normas 
gerais, serão aplicáveis a todas as instâncias educacionais; por outro lado, quando explicitarem diretrizes e bases em atos administrativos normativos, somente incidirão sobre o sistema federal de ensino (Ranieri, 2000 , p. 145-146). As citadas funções redistributiva e supletiva de assistência técnica e financeira aos demais entes federados visam a todos os sistemas de ensino $\left(\mathrm{CR} / 88\right.$, art. $\left.211, \S 1^{\circ}\right)$, assegurando o padrão mínimo de qualidade e a equalização de oportunidades educacionais, para evitar uma amplitude indeterminada a esta atribuição específica. Em qualquer caso, os limites contidos no ordenamento jurídico brasileiro devem ser respeitados.

Ao MEC cabe o exercício das competências inerentes ao Poder Público Federal em questões educacionais. Desse modo e segundo o art. $6^{\circ}$ da Lei $n^{\circ} 4.024 / 61$, cuja redação atual foi outorgada pelo art. $1^{\circ}$ da Lei $n^{\circ}$ 9.131/95, o MEC formula e avalia a política nacional de educação, ${ }^{13}$ garantindo a qualidade do ensino, mediante o auxílio do Conselho Nacional de Educação - CNE (Leis no 4.024/61, art. 6º , $^{\circ}$, e no 9.394/96, art. $\left.9^{\circ}, \S 1^{\circ}\right)$.

O § $2^{\circ}$ do art. $9^{\circ}$ da LDB prevê o fornecimento livre de informações relativas à educação brasileira, de modo a subsidiar a política nacional de mesma natureza, articulando e coordenando os distintos níveis e sistemas de ensino. A efetivação do comando legal ficou a cargo do Instituto Nacional de Estudos e Pesquisas Educacionais Anísio Teixeira (Inep), autarquia federal vinculada ao MEC, instituída pela Lei no 9.448, de 14 de março de 1997. Além de coletar, analisar e publicar os dados sobre educação, o Inep também coordena a avaliação dos cursos de graduação e estabelece parâmetros, critérios e instrumentos aos exames de acesso ao ensino superior, respeitando sempre a autonomia universitária.

Já o § $3^{\circ}$ do art. $9^{\circ}$ da LDB permite a delegação das competências da União aos Estados membros, com a finalidade de se "autorizar, reconhecer, credenciar, supervisionar e avaliar, respectivamente, os cursos das instituições de educação superior e os estabelecimentos do seu sistema de ensino" (LDB, art. 9 ${ }^{\circ}$ inciso IX). Assim, se o ente federado estadual ou distrital possuir IES em seu sistema (LDB, art. 10, inciso IV), ele também poderá avaliar cursos do sistema federal mediante delegação do Governo Central.

Para Ranieri (2000, p. 148), por meio do mencionado art. $9^{\circ}, \S 3^{\circ}$, da LDB, dever-se-ia vincular as IES privadas aos sistemas de avaliação estaduais nos quais se inserem suas sedes, sob a justificativa de que a "formulação de uma política de ensino e de aperfeiçoamento de pessoal, coerente e eficaz, pelos Estados, não se faz sem o controle do conjunto dos fatores que interferem em seus sistemas de ensino". Em continuação, a autora afirma que a organização federativa do Brasil não autoriza a inserção das IES particulares no sistema educacional federal e, muito menos, a excessiva competência normativa do Governo Federal, já que a autonomia político-administrativa dos entes federados está positivada no art. 18 da CR/88 e porque o art. 209, inciso II, da CR/88 não definiu qual nível de governo providenciaria a avaliação de qualidade nas IES privadas.

\footnotetext{
${ }^{13}$ Ranieri define política pública, no âmbito jurídico, como um programa de ação composto por "um conjunto de normas e atos, unificados em torno de uma dada finalidade, ainda que tais atos e normas sejam de natureza heterogênea e se submetam a regimes jurídicos próprios" (Ranieri, 2000, p. 146). De qualquer forma, o estudo da política pública analisa as atividades concretas de um governo, seu processo decisório, as possíveis alternativas e avaliação dos seus resultados
} 
14 Para se aprofundar no tema da aplicabilidade das normas constitucionais, ver José Afonso da Silva (2002, p. 81-164).

${ }^{15}$ Cabe salientar a classificação portuguesa de normas preceptivas, normas programáticas, normas autoexequíveis e normas heteroexequíveis, que acaba por conduzir à trilogia de normas constitucionais: preceptivas autoexequíveis, preceptivas heteroexequíveis e programáticas (sempre heteroexequíveis), prevista por Miranda (1996, p. 243-250; no mesmo sentido, Gouveia, 2005a, p. 708-712). Miranda (1996) apresenta a semelhança entre as classificações brasileira e portuguesa quando menciona: "Ora, verifica-se com relativa facilidade que as normas de eficácia plena de José Afonso da Silva correspondem às normas exequíveis de que acabamos de falar, as normas declaratórias de princípios institucionais e organizatórios correspondem grosso modo às normas preceptivas não exequíveis e as normas declaratórias de princípios programáticos às normas programáticas. Só as normas de eficácia contida ficarão à margem, embora pareçam reconduzir-se ainda a normas preceptivas" (Miranda, 1996, p. 249).
Com isso, a organização política brasileira exigiria da União a legislação genérica e nunca a normatização regional e peculiar aplicável às IES particulares localizadas nos territórios dos Estados membros, fomentando o regime de colaboração entre as entidades federadas.

Não obstante, cabe discordar parcialmente da supramencionada argumentação. É sabido que a União é competente para estabelecer normas gerais, diretrizes e bases da educação nacional, nos termos dos arts. 22, inciso XXIV, e 24, inciso IX e $\S \S 1^{\circ}$ a $4^{\circ}$, da CR/88. A avaliação da qualidade do ensino nas IES tem natureza de norma principiológica e, portanto, geral - logo, é da competência do Governo Federal. Decorre do princípio educacional da garantia do padrão de qualidade (CR/88, arts. 206, inciso VII, 209, inciso II, e 211, § 1º), normas constitucionais de eficácia plena, ${ }^{14}$ ou seja, preceptivas autoexequíveis. ${ }^{15}$ Além disso, passados 11 anos de vigência da LDB, aprovada a Lei no 10.861/04 e após grande investimento e evolução do sistema nacional de avaliação da educação superior, a realidade comprova, inequivocamente, as melhores condições da União em avaliar as IES públicas e privadas.

De maneira que seria conveniente, por questões orçamentárias e de manutenção do padrão de qualidade, em tais instituições, que todas estivessem submetidas ao Sistema Nacional de Avaliação da Educação Superior (Sinaes), evitando eventual descentralização e confusão nesta questão basilar. Sugere-se, então, uma alteração da LDB, no inciso IV do seu art. 10, para que passe a ter a seguinte redação: "Art. 10. Os Estados incumbir-se-ão de: [...] IV - autorizar, reconhecer, credenciar, supervisionar e avaliar os estabelecimentos do seu sistema de ensino, ressalvados os cursos das instituições de educação superior;". Como consequência, também haveria a necessidade de adaptação dos arts. 9 ${ }^{\circ}$ inciso VIII, e 16, inciso II, da LDB, para, respectivamente: "Art. 9. A União incumbir-se-á de: [...] VIII - assegurar processo nacional de avaliação das instituições de educação superior;" e "Art. 16. O sistema federal de ensino compreende: [...] II - todas as instituições de educação superior;". Coloca-se de manifesto que essa sugestão não violaria o art. 18 da CR/88, ante a natureza diretiva dos critérios e procedimentos de avaliação do ensino superior.

Aos Estados membros foram estabelecidas as competências enunciadas no art. 10 da LDB. Segundo Ranieri (2000), o art. 18 da CR/88 demonstra consonância com os incisos I, IV e V do mencionado art. 10 da LDB, enquanto os demais encargos são respaldados pelos arts. 211 e 214 da CR/88.

$\mathrm{O}$ art. 11 da LDB, antes citado, determina que os Municípios somente possam atuar na educação superior quando cumprirem com os comandos constitucionais pertinentes, isto é, pleno fornecimento do ensino fundamental e da educação infantil (CR/88, art. 211 , § $\left.2^{\circ}\right)$, bem como emprego de parcela superior aos $25 \%$ da receita resultante dos impostos (CR/88, art. 212). Assim:

A LDB, nesse passo, acentua o papel dos Municípios em relação à educação básica, confirmando a tendência notada no moderno 
federalismo de se atribuir necessidades básicas da população à menor esfera de governo, dentro de um modelo de colaboração entre os entes federados, conforme dispõe o princípio da subsidiariedade; o que não permite o descomprometimento da União, ou mesmo dos Estados, como se depreende do artigo 211 da Constituição Federal e do artigo 75 da LDB, que determinam o exercício da ação supletiva e redistributiva da União e dos Estados de modo a corrigir, progressivamente, as disparidades de acesso e garantir o padrão mínimo de qualidade de ensino. (Ranieri, 2000, p. 151).

Como se pode verificar, todas as entidades federadas possuem a atribuição de organizar, manter e desenvolver os órgãos e instituições oficiais de seus sistemas educacionais, segundo determinações do art. 212 da CR/88.

\section{Considerações finais}

Pode-se concluir que as normas constitucionais educacionais classificam-se, quanto à aplicabilidade, de diversas formas. Todavia, os comandos constitucionais que determinam a avaliação de qualidade pela Administração Pública (CR/88, arts. 206, inciso VII, 209, inciso II, e 211, $\S 1^{\circ}$ ) possuem eficácia plena, ou seja, não estão sujeitos à restrição ou à regulamentação por outras normas infraconstitucionais para serem aplicados.

A previsão plural das competências das entidades federadas na LDB, mediante atuação harmônica entre tais entes, não se efetivou, pois o poder genérico de coordenação das políticas públicas nacionais acabou por concentrar atribuições na União. Aos demais membros da Federação sobraram as funções normativas e organizativas, inerentes à administração de seus sistemas de ensino, em suas peculiaridades e localidades, desde que cumpram integralmente a LDB e o PNE.

Nesse contexto, os processos periódicos de avaliação de IES, cursos superiores e discentes, insertos no sistema federal de ensino, ficaram a cargo da União, por meio de seu MEC e respectivos órgãos de assessoramento, entre eles a Câmara de Educação Superior (CES) do CNE, a Comissão Nacional de Avaliação da Educação Superior (Conaes) e o Inep, para se estabelecer as prioridades e garantir a melhoria da qualidade do ensino, utilizando-se das informações e dados fornecidos por todas as instituições e órgãos educacionais. Ocorre que as normas gerais foram exaustivamente detalhadas na legislação federal, outorgando amplas competências regulamentares à União e, indiretamente, ao MEC e ao CNE, o que ensejou a ineficácia das regras descentralizadoras. Portanto, essa situação induz a um grande controle sobre a expansão da educação superior, especialmente no segmento particular, pois, no público, a União e os Estados membros atuam livremente, ante a organização federativa prevista na CR/88.

Sem embargo, com a aprovação da Lei no 10.861/04, a avaliação da educação superior adquiriu caráter sistêmico, conjugando situações, instrumentos avaliativos distintos e informações, em apenas uma análise 
globalizada, pela primeira vez positivada em lei federal. Instituiu-se, então, a avaliação a cargo do Inep, segundo diretrizes da Conaes, o que garante a integração das políticas públicas, do processo avaliativo e dos resultados conseguidos nos procedimentos regulatórios, para que a educação superior brasileira atinja elevados padrões de qualidade. Tais elementos vêm se refletindo nas discussões sobre o Projeto de Lei de Reforma Universitária (Brasil. Projeto de lei no 7.200, 2006).

Dessa forma, os resultados obtidos no Sinaes serão aplicados aos atos autorizativos de regulação de IES (Decreto no 5.773/06), para assegurar a expansão qualitativa de matrículas na educação superior, fortalecendo um sistema de avaliação unificado, consolidado e compatível com a realidade brasileira. Como consequência do grande investimento e da evolução do sistema nacional de avaliação da educação superior, a realidade demonstra, sem sombra de dúvida, as melhores condições do MEC, do CNE, da Conaes e do Inep em avaliar as IES, privadas e públicas, federais, estaduais ou municipais. Seria conveniente, em função de questões orçamentárias e de manutenção do padrão de qualidade, em tais instituições, que todas estivessem submetidas ao Sinaes, evitando a descentralização e a confusão nesta questão basilar. Entende-se que a avaliação qualitativa da educação superior é norma principiológica e geral, cabendo à União sua iniciativa (CR/88, arts. 22, inciso XXIV, e 24, inciso IX e $\S \S 1^{\circ}$ a $4^{\circ}$ ) e regulamentação. Deriva, ainda, do princípio educacional da garantia do padrão de qualidade, em conformidade com os arts. 206, inciso VII, 209, inciso II, e 211, § 1 da CR/88, que são normas constitucionais preceptivas autoexequíveis. Como o Projeto de Lei de Reforma Universitária ainda está no Congresso Nacional, sugere-se uma modificação na LDB, para que, no inciso IV do seu art. 10, passe a constar: "IV - autorizar, reconhecer, credenciar, supervisionar e avaliar os estabelecimentos do seu sistema de ensino, ressalvados os cursos das instituições de educação superior". Como consequência, também haveria a necessidade de adaptação dos arts. $9^{\circ}$, inciso VIII, e 16, inciso II, da LDB, para, respectivamente: "Art. $9^{\circ}$. A União incumbir-se-á de: VIII - assegurar processo nacional de avaliação das instituições de educação superior;" e "Art. 16. O sistema federal de ensino compreende: II - todas as instituições de educação superior;".

Finalmente, saliente-se que, nesta hipótese, não haveria qualquer violação ao princípio constitucional federativo (CR/88, art. 18), tendo em vista a índole diretiva dos critérios e procedimentos de avaliação do ensino superior.

\section{Referências bibliográficas}

BARACHO, José Alfredo de Oliveira. O princípio de subsidiariedade: conceito e evolução. Rio de Janeiro: Forense, 2000. 98 p.

BOAVENTURA, Edivaldo Machado. A educação brasileira e o direito. Belo Horizonte: Nova Alvorada, 1997. 352 p. 
BRASIL. Conselho Nacional de Educação (CNE). Câmara de Educação Básica (CEB). Parecer nº 30, de 12 de setembro de 2000. União Nacional dos Conselhos Municipais de Educação e Outros/SC solicita pronunciamento, tendo em vista o Parecer CEB 04/2000. Documenta, Brasília, n 468, p. 19-37, set. 2000.

BRASIL. Constituição da República Federativa do Brasil. Brasília: Senado Federal, Centro Gráfico, 1988. 292 p.

BRASIL. Decreto no 5.773, de 9 de maio de 2006. Dispõe sobre o exercício das funções de regulação, supervisão e avaliação de instituições de educação superior e cursos superiores de graduação e sequenciais no sistema federal de ensino. Diário Oficial da União, Brasília, 10 maio 2006. Disponível em: <http://www.planalto.gov.br/ccivil_03/_Ato20042006/2006/Decreto/D5773.htm>. Acesso em: 18 mar. 2008.

BRASIL. Lei no 4.024, de 20 de dezembro de 1961. Fixa as diretrizes e bases da educação nacional. Diário Oficial da União, Brasília, 27 dez. 1961. Disponível em: <http://www.planalto.gov.br/ccivil_03/Leis/ L4024.htm>. Acesso em: 13 jan. 2008.

Lei $n^{\circ}$ 9.131, de 24 de novembro de 1995. Altera dispositivos da Lei $n^{\circ} 4.024$, de 20 de dezembro 1961, e dá outras providências. Diário Oficial da União, Brasília, edição extra, 25 nov. 1995. Disponível em: <http://www.planalto.gov.br/ccivil_03/Leis/L9131.htm>.

Lei no 9.394, de 20 de dezembro de 1996. Estabelece as diretrizes e bases da educação nacional. Diário Oficial da União, Brasília, 23 dez. 1996. Disponível em: < http://www.planalto.gov.br/ ccivil_03/Leis/L9394.htm>.

Lei no 9.448, de 14 de março de 1997. Transforma o Instituto Nacional de Estudos e Pesquisas Educacionais (Inep) em autarquia federal e dá outras providências. Diário Oficial da União, Brasília, edição extra, 15 mar. 1997. Disponível em: < http://www.planalto.gov. br/ccivil_03/Leis/L9448.htm>. Acesso em: 3 fev. 2008.

Lei no 10.172, de 9 de janeiro de 2001. Aprova o Plano Nacional de Educação e dá outras providências. Diário Oficial da União, Brasília, 10 jan. 2001. Disponível em: <http://www.planalto.gov.br/ CCIVIL/LEIS/LEIS_2001/L10172.htm>. Acesso em: 2 jul. 2008.

Lei $\mathrm{n}^{\circ}$ 10.861, de 14 de abril de 2004. Institui o Sistema Nacional de Avaliação da Educação Superior (Sinaes) e dá outras providências. Diário Oficial da União, Brasília, 15 abr. 2004. Disponível em: <http://www.planalto.gov.br/ccivil_03/_Ato2004-2006/2004/Lei/ L10.861.htm>. 
BRASIL. Lei no 11.274 , de 6 de fevereiro de 2006. Altera a redação dos arts. 29, 30, 32 e 87 da Lei no 9.394, de 20 de dezembro de 1996, que estabelece as diretrizes e bases da educação nacional, dispondo sobre a duração de 9 (nove) anos para o ensino fundamental, com matrícula obrigatória a partir dos 6 (seis) anos de idade. Diário Oficial da União, Brasília, 7 fev. 2006. Disponível em: < http://www.planalto.gov.br/ ccivil_03/_Ato2004-2006/2006/Lei/L11274.htm>.

BRASIL. Projeto de lei no 7.200/2006 [Projeto de Lei de Reforma Universitária]. Estabelece normas gerais da educação superior, regula a educação superior no sistema federal de ensino, altera as Leis ${ }^{\text {os }}$ 9.394, de 20 de dezembro de 1996; 8.958, de 20 de dezembro de 1994; 9.504, de 30 de setembro de 1997; 9.532, de 10 de dezembro de 1997; 9.870, de 23 de novembro de 1999; e dá outras providências. Disponível em: <http://www.planalto.gov.br/ccivil_03/Projetos/PL/2006/ msg449-060608.htm>.

BRZEZINSKI, Iria (Org.). LDB interpretada: diversos olhares se entrecruzam. 8. ed. São Paulo: Cortez, 2003.

CANOTILHO, José Joaquim Gomes. Direito constitucional. 6. ed. Coimbra: Almedina, 1993. 1230 p.

FERRAZ, Esther de Figueiredo. Os sistemas de ensino federal e locais e as respectivas esferas de competência. In: PRADE, Péricles (Org.). Estudos jurídicos em homenagem a Vicente Rao. São Paulo: Resenha Universitária, 1976. p. 165-189.

GOUVEIA, Jorge Bacelar. Manual de direito constitucional: introdução, parte geral, parte especial. Coimbra: Almedina, 2005a. v. I. 768 p.

. Manual de direito constitucional: introdução, parte geral, parte especial. Coimbra: Edições Almedina, 2005b. v. II. 1536 p.

MAXIMILIANO, Carlos. Hermenêutica e aplicação do direito. 17. ed. Rio de Janeiro: Forense, 1998. 426 p.

MIRANDA, Jorge. Manual de direito constitucional: constituição e inconstitucionalidade. 3. ed. Coimbra: Coimbra Editora, 1996. Tomo II. $548 \mathrm{p}$.

. Manual de direito constitucional: actividade constitucional do Estado. 2. ed. Coimbra: Coimbra Editora, 2000. Tomo V. 428 p.

PONTES DE MIRANDA, Francisco Cavalcanti. Comentários à Constituição de 1967: arts. 157-189. São Paulo: Revista dos Tribunais, 1968. Tomo VI. 602 p. 
RANIERI, Nina Beatriz. Educação superior, direito e Estado na Lei de Diretrizes e Bases (Lei no 9.394/96). São Paulo: Edusp, Fapesp, 2000. 408 p.

ROCHA, Cármen Lúcia Antunes. República e federação no Brasil: traços constitucionais da organização política brasileira. Belo Horizonte: Del Rey, 1997. 328 p.

SAVIANI, Dermeval. Da nova LDB ao novo Plano Nacional de Educação: por uma outra política educacional. 5. ed. Campinas: Autores Associados, 2004.

SILVA, De Plácido e. Jurisdição. In: Vocabulário jurídico. 14. ed. Rio de Janeiro: Forense, 1998a. p. 466-468.

. Sistema. In: . Vocabulário jurídico. 14. ed. Rio de

Janeiro: Forense, 1998b. p. 761-762.

SILVA, José Afonso da. Aplicabilidade das normas constitucionais.

6. ed. São Paulo: Malheiros, 2002. 280 p.

Curso de direito constitucional positivo. 10. ed. São Paulo:

Malheiros, 1995. 824 p.

Magno Federici Gomes, pós-doutor em Direito Público e Educação pela Universidade Nova de Lisboa, Portugal, é professor adjunto da Pontifícia Universidade Católica de Minas Gerais (PUC-MG) e professor titular da Faculdade de Direito Padre Arnaldo Janssen.

magnofederici@hotmail.com

Recebido em 6 de julho de 2009.

Aprovado em 16 de setembro de 2010. 